\title{
Socioeconomic Challenges - A Global Perspective Evaluating Invisible Connections-Resolutioning Necessary Global Collaborative
}

\author{
Erin M. Nelson
}

Founder, Developer, Al Techlnologist, IWR DRMS; Co-organizer Netsquared NL, USA

\begin{abstract}
The author proports to you that currently held views of nations and governments as possessive in singular economics, as well as resulting socioeconomic behaviors and challenges, is in fact mistaken from the onset.

Herein she endeavors the task, through the course of this research and it's presentation to bring to light an awareness and understanding the interconnections of a singular and reactionary system. Separate only in the minds of nations this system is wholly interdependent and reactionary, as such it is merely a singular spoke of a global collective. Further as socioeconomic challenges among nations are equally diverse and interconnected, reactionary and affecting of the whole: internal communal and societal degradation, weakening financial systems, repressive and proportional representation systems and the rise of radical extremism.
\end{abstract}

Reactionary of the whole, the causation and resolutioning then too must come of the whole. A single unified global action effective of a singular unified system.

Keywords: socioeconomic challenges, global partnership, development.

JEL Classification: O1.

(C) The Author, 2017. This article is published with open access at ARMG Publishing.

\section{Introduction}

Socioeconomics (also known as social economics) is the social science that studies how economic activity affects and is shaped by social processes. In general it analyzes how societies progress, stagnate, or regress because of their local or regional economy, or the global economy (Webster Online Dictionary).

Socioeconomics stemming reactionary as a result of economy. Yet if regional and national economy are not a singular system, and as regional and national state or strength, the stability of which too is wholly interdependent and reactionary. It therefore can not support its claim of operational economic individuality.

\section{Liturature review}

If the Earth must lose that great portion of its pleasantness which it owes to things that the unlimited increase of wealth and population would extirpate from it, for the mere purpose of enabling it to support a larger, but not a better or a happier population, I sincerely hope, for the sake of posterity, that they will be content to be stationary, long before necessity compels them to it.

\section{John Stuart Mill, Principles of Political Economy, 1848.}

The world has entered an era of challenge arising from diverse but inter-related socio economic issues that have implications for all parts of the globe.

As individual nations and governments seek solutions in the domestic and foreign aftermath, all recommendations of independent action can not help but fall short.

You see while each nation views itself individually as it views each other nation individually, it is simply not the case. Individuality of system is a claim based on emotional need to view it as such. The truth in this matter is found easily in the wholly reactionary status which is variable and wholly dependant upon the status of other claimed individual systems, proving that both, are indeed conjoined parts of a whole. If viable solutions are to be reached, we must first begin to understand the invisible tethers to which we are collectively and collaboratively bound. 
The World Commission on Environment and Development (WCED), which defined "sustainable development" as a process that "meets present needs without compromising the ability of future generations to meet their own needs."This approach is strongly bottom-up - it suggests that a sustainable future will come into being if the biophysical and social conditions needed to support economic activity and human flourishing are maintained from each generation to the next. In addition, it emphasizes meeting needs rather than promoting growth or satisfying consumer preferences as the defining characteristic of "development."

The latter part of 2016 ushered in a new era for the world that was widely unanticipated. For many, late 2016 had been the point at which the world would have fully recalibrated from the damages which began 10 years ago.

A single entity, one company's failure stopped global financial activity, throwing economies worldwide into a still felt tailspin.

The global recession which began in 2007 at the failure of a single entity, Lehman Brothers, initiated a reactionary chain of events. A wave of devastation felt around the world which is still being felt a decade later. Instead of the anticipated confidence claimed of recovery, there is an era of fresh uncertainty and challenge.

Until we begin to assess socioeconomics as a single unit, separated yet intercorrelated, then the challenges arising of socio economic issues shall continue to escalate. These include but are not limited to political, military, government, economy, resources, employment, homelessness, crime, violent crime, family solidarity, abuse, emotional decay, communal degradation, societal degradation. Even the rise and expanse of mafia, cartel, ISIS are all interlinked and the resolution may only be found in globalized effort restoring the balance of power as relative to confidence in self safety, and the ability of community felt strength in government support where defense remains necessary; and in resource, as relative to life existent minimum requirements, agriculture, water, shelter. Only when the balance of power (confidence) and resource is restored will we begin to see not only true economic recovery and sustainable growth, we shall also see an end to radical extremism in numbers of force. While it can not and does not claim any alteration of political environments, it abolishes the environments from which they recruit. This removed, in longevity they simply can not exist.

Militarily an awareness of ongoing socioeconomic challenges in zones of conflict as well as in the countries where recruits are being bred is as essential as precision-bombing the enemy's training camp.

Yet in action we casually dismiss global poverty and wrecked economies as contributing drivers at our own peril. Extremism doesn't happen in a vacuum - it happily feeds off the dashed dreams of the jaded and dispossessed: Economies do not boon or wain of their own accord but at the stimulus of outside sources.

A community low in supply as a habit long endured does not suddenly go rogue if tomorrow stands similar of today, but for one that has never known hunger faced with the starvation of his children.

Minutes from NATO in meeting 2014

"We sit in the middle of an ongoing economic crisis, socio-economic issues have been forced into the limelight.

At first glance, the global financial crisis has certainly brought about distinctive conditions. These include:

A widespread lack of economic growth, youth unemployment rates of over 50\% in countries like Spain and Greece increasing levels of anti-austerity unrest across Europe, and rumours of contingency plans to restrict immigration in countries in the event of a financial collapse.

Does the current socio-economic landscape create the perfect storm for domestic, home-grown terrorist group recruitment? The resounding response to this question is 'perhaps'.

Current thought is evolving in respect to this question. There is now a more nuanced discussion of the similarities and differences between domestic terror and international terror. There's a move away from simply asking 'if' to asking 'how' socio-economic factors might influence participation in or support for terrorists groups."

\section{Methods}

Research \& Politics

Socioeconomic status and corruption perceptions around the world 
Why do nations and citizens vary in their perceptions about the frequency of corruption? Perhaps out of the varying degrees to which they are harmed by the corruption. Socioeconomically disadvantaged - more readily experiencing the result, would then perceive corruption to be more frequent.

Using multiple cross-national surveys, we find that the poor and the uneducated tend to perceive higher levels of corruption than the wealthy and the well educated. However, this relationship only holds in countries at high levels of economic development.

Even if the United States and its allies continue to retake territory from Daesh (or ISIS) and are able to disrupt other terrorist organizations, the problems of violent Islamist extremism and the societal and demographic conditions that enable it will persist. This volume seeks to define the problem and set it in context, and to offer some paths and priorities for the next president and her or his administration, including in the emerging and promising field of countering violent extremism (CVE). In poorer countries, the statistical relationship is much weaker and sometimes runs in the opposite direction.

\section{Results}

While a naive hearts-and-minds military strategy might not be applicable in this particular situation, an awareness of ongoing socioeconomic challenges in zones of conflict as well as in the countries where recruits are being bred is as essential as precision-bombing your enemy's training camp.

Hence, we casually dismiss global poverty and wrecked economies as contributing drivers of terrorism at our own peril. Extremism doesn't happen in a vacuum - it happily feeds off the dashed dreams of the jaded and dispossessed:

Many branches of science, especially those aimed at conservation, already understand the global connection and actively initiate collaboration in accounting socioeconomic environments in their efforts.

International collaboration can be crucial in determining the outcomes of conservation actions. Here, we propose a framework for incorporating demographic, socioeconomic, and political data into conservation prioritization in complex regions shared by multiple countries. As a case study, we quantitatively apply this approach to one of the world's most complex and threatened biodiversity hotspots: the Mediterranean Basin. Our analysis of 22 countries surrounding the Mediterranean Sea showed that the strongest economic, trade, tourism, and political ties are clearly among the three northwestern countries, of Italy, France, and Spain. Although economic activity between countries is often seen as a threat, it may also serve as an indicator of the potential of collaboration in conservation. Using data for threatened marine vertebrate species, we show how areas prioritized for conservation shift spatially when economic factors are used as a surrogate to favor areas where collaborative potential in conservation is more likely from the journal of Marine Sciences April 2015.

What then is the proposed government economic solution to a psycho social economic dysfunction.

Based on a dynamic simulation model in which businesses and households make myopic decisions without regard for the long-run implications of short-run production and consumption, Meadows et al. predicted that natural resource depletion and environmental degradation would lead to an irreversible collapse of the global economy by the early twenty-first century. In this analysis, avoiding catastrophe would be possible if and only if:

1. Human fertility was limited to the replacement rate to stabilize population.

2. Natural resource use and pollution per unit of industrial output was cut by at least 75 percent.

3. Industrial production was stabilized at the level prevailing in the late twentieth century.

4. Goods and services were redistributed from the rich to the poor to provide a high quality of life for all members of the global community.

This vision is fascinating in multiple respects. It is simultaneously dystopian and utopian, presenting a narrative that combines an apocalyptic warning with the possibility of a type of secular renewal achieved through a process of personal and (especially) collective transformation. Like Pinchot and the WCED, this vision emphasizes the need to conserve natural resources and ecosystems as the foundation of a sustainable future, combined with the need to redistribute wealth to achieve equity in an ecologically limited world (Rich Howarth, 2012). 


\section{Discussion and conclusions}

On the topic of economy, governments, researchers and vocational participants all will quickly stand in agreement as a system constantly in flux, pro or con, reactionary of multi dependant stimulus far exceeding regional bounds.

We easily recognize the pattern of economical systems as regional cogs decisioning independently yet statused as reactionary, an interconnected piece of the whole.

In a discussion of economics we will without hesitation recognize the affect nation upon nation in the overall status and health.

Yet enter the same proponents into a discussion of socioeconomic challenges as a reactionary system, global effective, heads drop, mouths close. Solutions seem far removed, outside of our capacity.

So long as we fail to recognize the global implications of degrading social economics, it shall remain so.

We must as a world of individual nations, begin awareness and collaborative efforts of global proportion, individually, collectively, governmentally and yes militarily, creating the paths to a sustainable earth. Providing recovered economics will by proxy yield improved psychosocial confidence, addressing resource, felt communal strengths improve, it's members once again confident, supportive one to another, they too shall stand. In this then is the potential of an increased state of peace. Let us then finally recognize our position to strengthen our system to the benefit of all nations. To coin an American phrase standing as truth in this and all things.

\section{References}

1. Chari, V.V., Christiano, L., and Kehoe, P. J. (2008). Facts and Myths about the Financial Crisis of 2008. Federal Reserve Bank of Minneapolis Research Department, Working Paper 666.

2. General Assembly Plenary 86th Meeting (16 February 2016). Links between Extreme Poverty, Violent Extremism Can Be Broken by Creating Jobs, Reducing Inequalities, General Assembly Hears as Debate Concludes. Retrieved from https://www.un.org/press/en/2015/ga11761.doc.htm.

3. Howarth Rich (2012). Sustainability, well-being, and economic growth. Minding Nature, 5(2). Retrieved from http://www.humansandnature.org/sustainability-well-being-and-economic-growth.

4. Rand Beers, Richard A. Clarke, Emilian Papadopoulos, and Paul Salem (2016). The Middle East and regional transition, terrorism, and countering violent extremism: what the next president will face. The ANNALS of the American Academy of Political and Social Science, 668(1).

5. Ravi Jagannathan, Mudit Kapoor and Ernst Schaumburg (2013). What Really Spurred the Great Recession? Kellog Insight. Retrieved from https://insight.kellogg.northwestern.edu/article/what_really_spurred_the_great_recession.

6. Tamara Kharroub (2015). Understanding Violent Extremism: The Social Psychology of Identity and Group Dynamics. Retrieved from http://arabcenterdc.org/research-paper/understanding-violentextremism-the-social-psychology-of-identity-and-group-dynamics/.

7. The European Institute of Peace. Retrieved from http://www.eip.org/\#1.

8. The Psychologic Basis of Social Economics. Retrieved from http://journals.sagepub.com/na101/home/literatum/publisher/sage/journals/content/anna/1893/anna_3_4/ $\underline{000271629300300405 / 20160831 / 000271629300300405 . f p . p n g \quad v 03 .}$ 